\title{
Inflammasomes in neuroinflammation and changes in brain function: a focused review
}

\author{
Gaurav Singhal ${ }^{1}$, Emily J. Jaehne ${ }^{1}$, Frances Corrigan ${ }^{2}$, Catherine Toben ${ }^{1}$ and Bernhard T. Baune ${ }^{1 *}$ \\ 'Psychiatric Neuroscience Lab, Discipline of Psychiatry, School of Medicine, University of Adelaide, Adelaide, SA, Australia \\ ${ }^{2}$ Discipline of Anatomy and Physiology, School of Medical Sciences, University of Adelaide, Adelaide, SA, Australia
}

\section{Edited by:}

Luba Sominsky, RMIT University,

Australia

Reviewed by:

Trisha Anne Jenkins, RMIT

University, Australia

Ruth M. Barrientos, University of

Colorado, USA

*Correspondence:

Bernhard T. Baune, Psychiatric Neuroscience Lab, Discipline of

Psychiatry, School of Medicine,

University of Adelaide, Level 4

Eleanor Harrald Building, North

Terrace, Adelaide, SA - 5005,

Australia

e-mail:bernhard.baune@

adelaide.edu.au
Recent literature has pointed to the existence of inflammasome-mediated inflammatory pathways in central nervous system (CNS) disorders and associated changes in behavior. Neuroinflammation, which is an innate immune response in the CNS against harmful and irritable stimuli such as pathogens and metabolic toxic waste, as well as to chronic mild stress, is mediated by protein complexes known as inflammasomes. Inflammasomes activate pro-inflammatory caspases 1 and 5 , which then cleave the precursor forms of pro-inflammatory cytokines IL-1 $\beta$, IL-18, and IL-33 into their active forms. These pro-inflammatory cytokines have been shown to promote a variety of innate immune processes associated with infection, inflammation, and autoimmunity, and thereby play an instrumental role in the instigation of neuroinflammation during old age and subsequent occurrence of neurodegenerative diseases, cognitive impairment, and dementia. In particular, NLRP inflammasomes may also have a role in the etiologies of depression, Alzheimer's disease (AD) and in metabolic disorders, such as Type II diabetes, obesity and cardiovascular diseases that have been shown to be co-morbid with psychiatric illnesses. It has been reported that while these inflammasomes may be activated through TNF- $\alpha$ dependent pathways, other cytokines, like IFN- $\gamma$, may assist in inhibiting their activation and thus delay disease progression. Furthermore, some other cytokines, including IL-6, may not have a direct role in inflammasome-mediated diseases. An array of recent research suggests that NLRP inflammasomes targeted therapies could be used for alleviating neuroinflammation and for treatment of associated psychiatric illnesses, although this still remains a challenge and necessitates further extensive research. This review examines the complex inflammatory signaling pathways involved in the activation of NLRP inflammasomes and the role they play in promoting neuroinflammation and subsequent behavioral changes.

\section{Keywords: inflammasomes, NLRP, neuroinflammation, cytokines, IL-1, aging, depression, Alzheimer's disease}

\section{INTRODUCTION}

The discovery of inflammasomes by Martinon et al. (2002) has prompted considerable interest in the role that inflammasomes play in the mechanism of inflammation and associated disease patterns. Of late, an emerging body of literature points to the existence of inflammasome-mediated inflammatory pathways in central nervous system (CNS) disorders.

Neuroinflammation is a known factor in the pathogenesis of neurodegenerative diseases (Frank-Cannon et al., 2009), and psychiatric illnesses such as depression (Walker et al., 2014), Alzheimer's disease (AD) (Pimplikar, 2014), Parkinson's disease (PD) (Hirsch et al., 2012), Huntington's disease (Möller, 2010), and multiple sclerosis (Frohman et al., 2006). It has also been implicated in sickness behavior (Biesmans et al., 2013), diminished cognition (Ownby, 2010), and memory (Hein and O'Banion, 2009), as well as in age-related increased sensitization of the immune system to extrinsic and intrinsic stimuli (Godbout et al., 2005; Sparkman and Johnson, 2008). Pattern recognition receptors (PRRs) play an integral role in the innate immune response through recognition of pathogen specific proteins (PAMPs) and damage associated proteins (DAMPs). They are primarily expressed by glial cells, macrophages and oligodendrocytes within the brain and can be membrane bound (toll-like receptors) or within the cytoplasm [Nod-like receptors (NLRs)]. Activation of these NLRs leads to the assembly and activation of cytosolic protein complexes known as inflammasomes which then enable the activation of pro-inflammatory caspases, particularly caspase- 1 . This then leads to the activation of pro-inflammatory cytokines interleukin (IL)-1 $\beta$, IL-18, and IL-33 (Arend et al., 2008; Chakraborty et al., 2010), which promote a number of innate immune processes associated with infection, inflammation and autoimmunity (Davis et al., 2011), thereby responsible for neuroinflammation and associated brain diseases (Tha et al., 2000; Cacquevel et al., 2004; Felderhoff-Mueser et al., 2005; Godbout and Johnson, 2009; Mawhinney et al., 2011; Zhang et al., 2014).

It has been known for some time that immunosenescence, in addition to neurodegenerative changes with age, predisposes 
the brain to higher risk of acquiring neuroinflammatory disorders. Considerable findings during the last decade have suggested an instrumental role of inflammasomes in the pathophysiology of neuroinflammation during neuronal ageing, and its associated neurodegenerative diseases such as dementia, leading to loss of memory and cognitive impairment (Simi et al., 2007; Chakraborty et al., 2010; Mawhinney et al., 2011; Liu and Chan, 2014). In particular, NLRP (NLR family, containing pyrin domain) inflammasomes have been shown to have a role in the etiologies of several neurological diseases such as depression (Zhang et al., 2014), AD (Tan et al., 2013), PD (Cedillos, 2013), and multiple sclerosis (Gris et al., 2010; Fischer et al., 2012). Systemically, NLRP inflammasome-driven inflammatory responses also play a role in the development of Type II diabetes (Grant and Dixit, 2013; Lee et al., 2013), obesity (Stienstra et al., 2011), and cardiovascular diseases (Garg, 2011), as well as cancer (Zitvogel et al., 2012). Given that metabolic disorders can predispose to the development of psychiatric disorders, it is possible that inflammasome-driven inflammatory pathways may be a potential mechanism driving this co-morbidity.

A number of studies have investigated the innate immune pathways associated with the activation of NLRP inflammasomes and the subsequent production of IL-1 $\beta$, IL-18, and IL-33 from their precursors. The aim of this review is to examine these complex inflammatory signaling pathways associated with NLRP inflammasomes activation, and leading to neuroinflammation and behavioral changes that have commonly been observed during various psychiatric disorders and brain aging.

\section{MATERIALS AND METHODS PRISMA CRITERIA}

The guidelines prescribed by PRISMA (Preferred reporting items for systematic reviews and meta-analyses) (Liberati et al., 2009; Moher et al., 2009) were followed while constructing this review. The checklist items from PRISMA as relevant to this review, for example those related to search and writing approaches, were included and the items not relevant, for example those related to meta-analyses, were excluded.

\section{SEARCH AND SELECTION PROCESS}

An electronic database search of PubMed and Google Scholar with several key terms in various permutations was performed. These included but were not limited to: inflammasomes, neuroinflammation, NLRP, NALP (NACHT, LRR, and PYD domains containing proteins), cytokines, IL-1, IL-18, IL-33, TNF, cellular, humoral, immune, aging, depression, AD, PD, Huntington's disease, multiple sclerosis, cognition, behavior, metabolic disorders, diabetes, obesity, cardiovascular disease, cancer, pathogen associated molecular patterns, damage associated molecular patterns, toll like receptors, and glial cells. At each stage of the search, titles and abstracts were scrutinized and the most appropriate organized into separate folders using End Note X6.0.1 software. In addition, articles relevant to our discussion were retrieved from the reference list of other online articles on each subtopic. This in total yielded 1563 papers. After placing all inclusion and exclusion criteria into our search (depicted in Figure 1), 164 articles closely related to the aims set forth for this review were selected and hence utilized.

\section{INCLUSION AND EXCLUSION CRITERIA}

The emphasis of this review has been on inflammatory pathways associated with inflammasome activity in the brain, and as such articles investigating inflammasomes, in particular NLRP inflammasomes and their mechanism of actions in CNS disorders were selected for detailed analysis. In addition, articles addressing the effects of IL-1 family of cytokines in the brain were read thoroughly to understand and analyze the various mechanisms of actions of these cytokines, especially in the brain and their association with inflammasomes. Other immune factors related to inflammasomes and the role of inflammasomes in systemic diseases was also investigated while writing this review. All articles included in this review have been published between 1989 and 2014. Articles without the full text available and with anecdotal evidence were excluded from the review.

\section{STRUCTURE OF NLRP INFLAMMASOMES}

The NLR family, pyrin domain containing inflammasomes (NLRP) are the most studied and best characterized protein complex during inflammation (Stutz et al., 2009). NLRs are intracellular PRRs and function in association with Toll-Like Receptors to sense the presence of PAMPs which are found in a variety of microorganisms that enter cell through phagocytosis (infectious stimuli), and DAMPs such as nuclear and cytosolic protein characteristics of tissue injury/stress (non-infectious stimuli). In turn, this activates the innate and acquired immune response (Inohara et al., 2005; Kanneganti et al., 2007; Franchi et al., 2009). A key part of this process is the assembly of inflammasome complexes that generally have three main components: a cytosolic PRR (either from the NLR family or the pyrin and HIN domain containing family-PYHIN), caspase-1 and an adaptor protein ASC (apoptosis-associated speck like protein). The NLR family contains a leucine rich repeat domain (LRR), a central NACHT domain and a variable amino-terminal domain, which in the NLRP subfamily is an N-terminal pyrin domain (PYD). Activation of NLRPs leads to the recruitment of ASC which contains a caspase activation and recruitment domain (CARD). ASC then interacts with the CARD of pro-caspase-1. There are exceptions to this sequence, with for example NLRP1, directly interacting with pro-caspase 1 , without necessarily needing ASC. Nonetheless the interaction with pro-capse-1 leads to its conversion to caspase 1 , which then converts pro forms of IL-1 $\beta$, IL-18, and IL-33 into their active forms, initiating an inflammatory response (Martinon et al., 2002; Petrilli et al., 2005).The NLRP3 is the largest and most studied inflammasome of all known at this stage (Stutz et al., 2009).

See Figure 2 for the schematic representation of the structures of different NLRP inflammasomes as described above.

\section{THE ROLE OF IL-1 FAMILY OF CYTOKINES IN INFLAMMATION, PATHOLOGICAL STATES, AND HOMEOSTATIC RESPONSE IN THE BRAIN}

Pro-inflammatory cytokines function to attract leucocytes and enhance their proliferation at the site of inflammation. They 


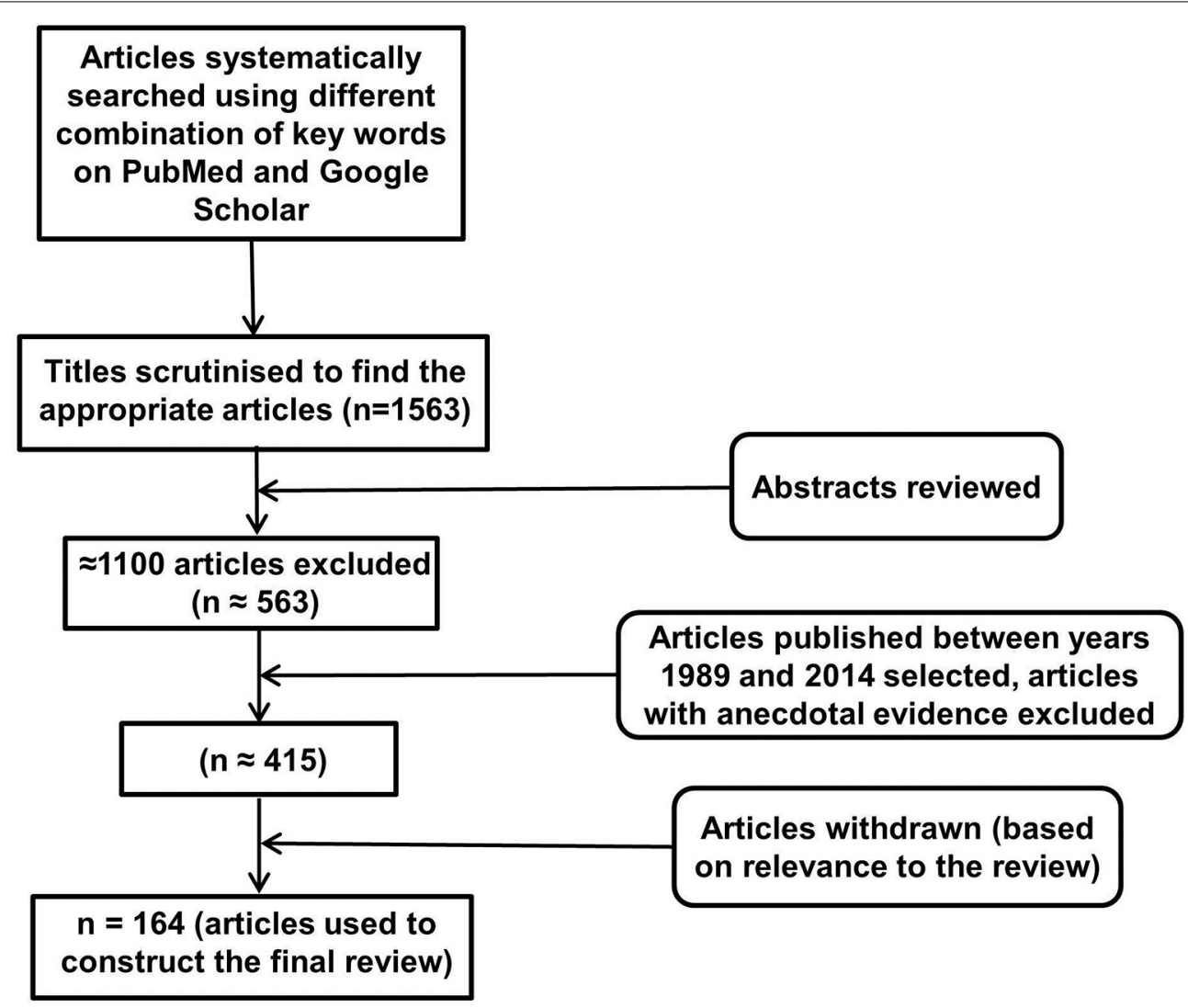

FIGURE 1 | Study inclusion flowchart. It depicts the methodology for search and collection of relevant articles for this review, following PRISMA guidelines (Liberati et al., 2009; Moher et al., 2009).

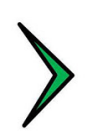

PYD

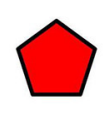

NACHT

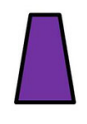

NAD<smiles>c1ccc(C2CCCCC2)cc1</smiles>

LRR

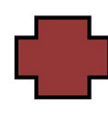

FIIND

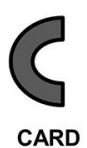

ropoopotse

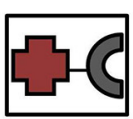

CARDINAL PROTEIN

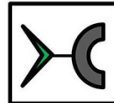

ASC/PYCARD

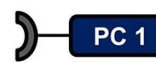

PC 5

PRO-CASPASE ENZYMES

\section{NLRP 1 inflammasome complex}
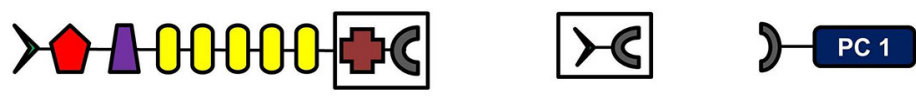

PC 5

\section{NLRP 2 and NLRP 3 inflammasome complex}

FIGURE 2 | Structure of NLRP inflammasomes. NLRP inflammasomes are intracellular protein complexes consisting of NLRP (NACHT, LRR, and PYD domains containing proteins 1, 2, or 3), the adapter protein ASC/Pycard, enzyme pro-caspases 1 and 5, and cardinal proteins. NLRP1 has Pyrin (PYD) domain on the amino (N)-terminal. This PYD domain is bonded to a NACHT domain followed by a NACHT-associated domain (NAD), several lucine-rich repeats (LRR), FIIND domain and the caspase recruitment domain (CARD) at the carboxy (C)-terminal. The molecular structures of NLRP2 and NLRP3 are similar to NLRP1, except that instead of being directly linked to FIIND domain, LRRs are linked to a cardinal protein which consists of FIIND domain on $\mathrm{N}$-terminal and CARD domain on the C-terminal. NLRPs with the adapter protein ASC/Pycard and pro-caspase enzymes form the inflammasome complex responsible for converting pro-IL-1 cytokines into their active forms within the cytoplasm of glial cells primarily. ASC, apoptosis-associated speck-like protein containing a CARD. 
stimulate cytotoxicity, release of proteolytic enzymes, synthesis of prostaglandins, and synthesis and secretion of secondary cytokines. This in turn promotes inflammation and increases thermoregulatory set point, generally associated with symptoms such as fever, tissue destruction, shock, and even death (Cannon, 2000). The IL-1 family of cytokines comprises 11 secreted factors, including IL- $1 \alpha$, IL-1 $\beta$, IL-18, and IL-33, which are known for playing a role in host defense and immune system regulation in inflammatory diseases (Barksby et al., 2007; Arend et al., 2008; Dinarello, 2009; Sims and Smith, 2010). These cytokines have been shown to be involved in a variety of immune reactions as well as in the initiation, regulation, and maintenance of inflammation (Dinarello, 2000). In particular, cytokine mediated processes have been shown to result in long term neuropsychiatric disorders and were found to be related to major depression, dementia, and AD (Licastro et al., 2000; Cacquevel et al., 2004; McAfoose and Baune, 2009). The presence of IL$1 \beta$ has been demonstrated in cerebrospinal fluid and plasma of patients with AD (Licastro et al., 2000; Tarkowski et al., 2003). Similarly, the roles of IL-18 and IL-33 in neuroinflammation and neurodegenerative diseases have also been well established (Felderhoff-Mueser et al., 2005; Arend et al., 2008; Liew et al., 2010).

However, it is important to note that although proinflammatory cytokines (IL-1 and TNF family of cytokines) have been shown to result in neuroinflammation and neurodegenerative diseases when expression is high, at constitutive levels they are required for normal physiological functioning, particularly in the molecular and cellular mechanisms responsible for learning, memory and cognition (McAfoose and Baune, 2009). They influence and maintain homeostasis in monoamine metabolism, neuronal genesis and survival, Hypothalamic-Pituitary-Adrenal (HPA) axis sensitivity to cortisol and certain cellular neuroimmune functions (Eyre and Baune, 2012). However, levels of both pro-inflammatory and anti-inflammatory cytokines have been shown to be elevated in many brain disorders, including $\mathrm{AD}, \mathrm{PD}$, and age related dementia, indicating their role in cognitive and memory deficits with age. When pro-inflammatory cytokines are overexpressed, anti-inflammatory cytokines potentially function to suppress the gene expression for pro-inflammatory cytokine production and control the pro-inflammatory response. For instance, gene knockout mice for anti-inflammatory cytokines, such as IL-1ra, IL-10, and TGF- $\beta 1$ showed enhanced inflammatory reactions (Dinarello, 2000). However, no study describes the effects of anti-inflammatory cytokines on activated inflammasomes. Activated microglia and astrocytes are the main source of cytokines in the brain (Rothwell et al., 1996; Hanisch, 2002).

Figure 3 shows the cytokine cascade in brain following stimulation with an infectious agent, metabolic waste or foreign material. As this includes increase in the levels of IL- $1 \beta$ cytokine which can only be activated from its precursor in the presence of enzyme caspase 1, it indicates an active involvement of inflammasome action during this cytokine cascade.

\section{LINK BETWEEN AGING OF BRAIN, IL-1 CYTOKINES, AND BRAIN DISORDERS}

Aging of the brain has been shown to be associated with many cognitive and memory deficit disorders and is believed to be regulated by extrinsic (e.g., environmental) and intrinsic (e.g., genotype) factors (van der Staay, 2002). Several brain disorders, such as $\mathrm{AD}$ and $\mathrm{PD}$, are the products of chronic neuroinflammation and resultant neurodegeneration (Heneka et al., 2010; Hirsch et al., 2012), the symptoms which are also common to the aging brain (McGeer and McGeer, 2004). Dementia, decline in cognitive abilities and impairment of spatial memory are often seen during aging and are associated with neuroinflammatory changes within the brain accumulated over a period of time. Indeed, a significant association has been found between age related depression and level of pro-inflammatory cytokines in the brain (Godbout et al., 2008). Moreover, the risk of infections increases with age, mainly due to immunosenescence (Aw et al., 2007) and a rise in circulating autoantibodies and lymphoproliferative disorders, hence contributing toward greater morbidity and mortality in old age (Shinkai et al., 1998; Senchina and Kohut, 2007).

Structural and functional changes in the brain are coordinated by a range of intracellular signaling molecules. Consistent findings suggest that an increase in the expression of proinflammatory cytokines by astrocytes and microglia within the brain results in neuroinflammation followed by neurodegeneration, eventually resulting in cognitive and memory deficit and exacerbated sickness and depressive-like behavior (Mrak and Griffin, 2005; Huang et al., 2008). Microglia are primed with aging and upon secondary stimulation, these microglia release excessive quantities of pro-inflammatory cytokines, such as TNF$\alpha$, IL-1 $\beta$, and IL-6 (Dilger and Johnson, 2008). The increase in the number of microglia, astrocytes and percentage of GFAP in the brain with age has been reported in rodents, which is subsequently found to be related to cognitive and memory impairment (Sugaya et al., 1996; Rozovsky et al., 1998), and to neurodegenerative diseases such as AD (Mrak and Griffin, 2005). The effects of aging on microglial functions in the brain has been reviewed in detail by Conde and Streit (2006). During aging, glial cells, particularly microglia show increased activation and expression of pro-inflammatory cytokines, such as IL-1, however, they also become increasingly dysfunctional and lose neuro-protective properties which predispose the brain to the neurodegenerative disorders in line with other genetic and acquired environmental risks (Mrak and Griffin, 2005; Streit, 2005). Similarly, astrocytes are the immune effector cells, which express cytokines (IL-1, IL6 , IL-10, interferons $\alpha$ and $\beta$, TNF $\alpha$ and $\beta$ ) and chemokines, and mediate inflammation and immune reactivity in the brain. The under-expression or over-expression of astrocytes can also lead to neurodegenerative diseases (Dong and Benveniste, 2001).

\section{INFLAMMASOME MEDIATED INFLAMMATORY PATHWAYS IN THE AGING BRAIN}

It was not known until recently whether inflammasomes play any role in causing or aggravating neuroinflammation during neuronal aging. Considerable recent findings have suggested an instrumental role of inflammasomes in the pathophysiology of neuroinflammation during neuronal ageing, and associated neurodegenerative diseases, cognitive impairment and dementia (Simi et al., 2007; Chakraborty et al., 2010; Mawhinney et al., 2011; Liu and Chan, 2014). There is upregulation in the expression of several genes that signal inflammasome assembly 


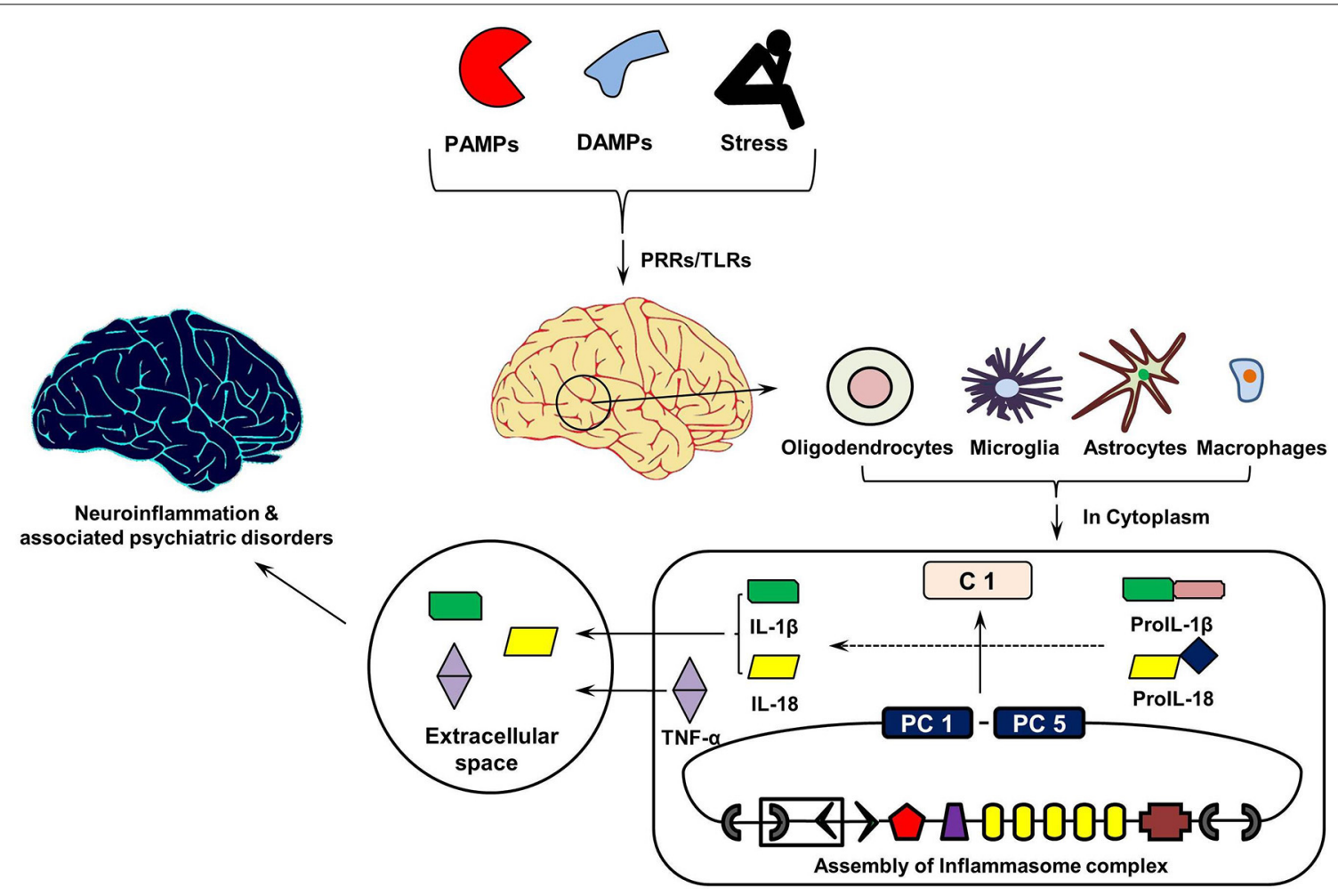

FIGURE 3 | Inflammasomes Cascade in Brain. On recognizing pathogen associated molecular patterns (PAMPs, found in phagocytized microorganisms) and damage associated molecular patters (DAMPs, e.g., nuclear and cytosolic proteins), intracellular pathogen recognition receptors (PRRs) and Toll-Like Receptors (TLRs) initiates assembly of cytosolic inflammasome complex. In turn, this activates the innate and acquired immune responses involving Interleukin (IL)-1 cytokines, which in addition to Tumor Necrosis Factor (TNF)- $\alpha$ initiate inflammatory reaction in the extracellular space. PC1 and PC5, Pro-caspases 1 and 5; C1, Caspase 1. and activation of caspase 1 (e.g., thioredoxin-interacting protein, P2X7, and pannexins), as well as signaling of TLRs (e.g., CD14, TLR2, TLR4, TLR7, TOLLIP, MYD88) in different regions of the brain such as hippocampus, post-central gyrus, and superior frontal gyrus during aging (Cribbs et al., 2012). TLRs are evolutionary conserved microbe specific structural motifs (e.g., PAMPs) and endogenous molecule (e.g., DAMPs) recognition transmembrane or endosomic membrane proteins, primarily expressed in various sentinel cells such as dendritic cells, macrophages, and plasmatoid dendritic cells that form the first line of defense (Kumar et al., 2009). The interaction between TLRs and LRRs on cytosolic NLRs trigger the assembly and activation of inflammasomes culminating in caspase 1 catalyzing pro-IL-1 cytokines into their active forms (van de Veerdonk and Netea, 2011). The increased activity of both TLRs and NLRs in the aging brain can therefore act as a deterrent to the negative regulation of their expression and a sustained expression could result in chronic neuroinflammation and associated neurodegenerative diseases. Moreover, production of reactive oxygen species (ROS) from dysfunctional mitochondria and increased NF- $\kappa \mathrm{B}$ signaling with aging could also potentiate the priming of NLRP3 inflammasomes in the brain resulting in an inflammatory response (Salminen et al., 2012). Formation of mutant $\alpha$-synuclein and $\mathrm{A} \beta$ fibrils, seen during $\mathrm{PD}$ and $\mathrm{AD}$ respectively, further pose greater danger in old age as they act to enhance the activity of inflammasomes in the brain (Salminen et al., 2009; Tschopp and Schroder, 2010; Cedillos, 2013).

Enhanced inflammasome activity could manifest in the form of cognitive decline in an aging population, as shown in 18 month old male Fisher 344 rats, however spatial learning improved when rats were treated with an anti-inflammatory drug probenecid (Mawhinney et al., 2011) which reduced NLRP1 inflammasome activation. However the mechanism for this is not yet completely understood.

\section{ASSOCIATION BETWEEN NEUROINFLAMMATION AND MAJOR DEPRESSIVE DISORDER}

Major depressive disorder (MDD) is characterized by a distinct change of mood accompanied by sadness, irritability, loss of interest in all activities and events, as well as psychophysiological changes (Belmaker and Agam, 2008). A number of studies, both experimental and meta-analytic, have revealed increased expression of pro-inflammatory cytokines, TNF- $\alpha$, IL- $1 \beta$, and IL-6, in the brain of MDD patients leading to neuroinflammation (Maes et al., 1997; Howren et al., 2009; Dowlati et al., 2010; Hannestad et al., 2011). Role of chronic mild stress in neuroinflammation and subsequent occurrence of depression has also been established (Farooq et al., 2012), although it is not clear if inflammasomes have any role in causing neuroinflammation in response to chronic mild stress. 


\section{INFLAMMASOME MEDIATED INFLAMMATORY PATHWAYS ASSOCIATED WITH MAJOR DEPRESSIVE DISORDER}

The increase in IL-1 $\beta$ levels and neuroinflammation in the brain of MDD patients potentially suggests a role for inflammasomes in MDD. Researchers have indeed recently shown the involvement of the NLRP3 inflammasome in lipopolysaccharide (LPS)induced mouse depressive-like behavior (Zhang et al., 2014). Similar findings were seen in human participants when activated NLRP3 inflammasomes were detected in blood mononuclear cells from depressive patients (Alcocer-Gómez et al., 2014). To investigate the etiological role of inflammasomes in depression, a panel of researchers conducted a clinical trial in major depression and schizophrenic patients. They concluded from the study that inflammasome-related inflammation is an ongoing process in psychiatric patients during diseased states (Hohmann et al., 2014). Moreover, the recent finding that mice lacking caspase1 are resistant to LPS-induced depressive-like behavior further supports the role of inflammasomes in depression (Moon et al., 2009). Some authors recently reviewed the role of inflammasomes in MDD and its comorbidity with systemic illnesses, and proposed a new inflammasome hypothesis of depression and related comorbid systemic illnesses (Iwata et al., 2013). The review highlights the central mediator role that inflammasomes play in the contribution of psychological and physical stressors to the development of depression and its association with systemic illnesses. The activation of inflammasomes, particularly NLRP3, therefore could be indirectly related to the pathophysiology of depression and its comorbidity with other systemic diseases through an inflammatory response in the brain.

\section{ASSOCIATION BETWEEN NEUROINFLAMMATION AND ALZHEIMER'S DISEASE}

$\mathrm{AD}$ is characterized by a debilitating chronic and progressive neurodegeneration leading to major clinical hallmarks of loss of memory, cognitive deficit, dementia, and behavioral impairment. Although, the prevalence of AD is higher in people over 60 and it increases proportionally with every 10 years of age (Younger/Early Onset Alzheimer's and Dementia: Alzheimer's Association, 2014), early onset of $\mathrm{AD}$ has also been reported in people in their 40 s and 50s (Kim et al., 2014). Several factors such as genetic predisposition (Bertram and Tanzi, 2009; Kamboh et al., 2012), reduced synthesis of excitatory neurotransmitter acetyl choline (Babic, 1999), extracellular deposition of amyloid beta $(A \beta)$ in the brain (Palop and Mucke, 2010), abnormalities in tau protein forming neurofibrillary tangles leading to disintegration of microtubules (Ballatore et al., 2007), and oxidative stress and inflammatory cascades mediated by primed glia cells (Agostinho et al., 2010) have been proposed to cause AD. These different hypotheses have been established after years of independent research; however, recent efforts toward finding the common link between the causal factors for $\mathrm{AD}$ have pointed toward the inflammatory cascade linking them in the brain. Indeed, damaged neurons, highly insoluble $\mathrm{A} \beta$ deposits and neurofibrillary tangles could provide stimuli for neuroinflammation (Wenk, 2003). Similarly, neurotransmitter acetylcholine has been shown to be involved in inhibiting the release of pro-inflammatory cytokines from microglia and monocytes (Tabet, 2006), an anti-inflammatory mechanism that could be disturbed during acetylcholine deficiency. This suggests that all above etiologies for $\mathrm{AD}$, when accompanied by chronic neuroinflammation, lead to progressive neurodegeneration and behavioral impairment with age, characteristics of symptoms of AD. In the absence of neuroinflammation, these etiologies may not provide sufficient pathology to cause $\mathrm{AD}$. This is supported by the finding that significant amyloid deposition could be present in the brain of healthy elderly individuals without cognitive impairment (Aizenstein et al., 2008). Likewise, while higher quantities of tau proteins have been reported in the brain of $\mathrm{AD}$ patients than unaffected individuals (Avila et al., 2004), some authors have challenged the tau protein hypothesis and proposed that tau phosphorylation is a compensatory mechanism to protect neurons against oxidative stress (Lee et al., 2005). Nonetheless, this suggests overall that a single factor alone may not be sufficient to cause $\mathrm{AD}$, and irrespective of the causative factor, neuroinflammation essentially provides a central pathway to the onset of $\mathrm{AD}$ which is mediated by various pro-inflammatory cytokines and chemokines, including IL-1 family of cytokines that are activated by inflammasomes.

Indeed, IL-1 $\beta$ and IL-18 over-expression has been shown to initiate inflammatory process in the brain of $\mathrm{AD}$ patients (RubioPerez and Morillas-Ruiz, 2012; Liu and Chan, 2014). This overexpression has been detected in microglia, astrocytes as well as neurons, and found to be co-localized with both $A \beta$ plaques and tau. Interestingly, it has also been suggested that chronic inflammation could be the cause for increase in $\mathrm{A} \beta$ and tau phosphorylation in the brain (Meraz-Ríos et al., 2013). In support of this, studies on transgenic mice with LPS-induced neuroinflammation have shown enhanced intracellular deposition of $\mathrm{A} \beta$ (Sheng et al., 2003; Lee et al., 2008) and tau phosphorylation (Kitazawa et al., 2005) in the brain of mice. Overall, this suggests a chain of continuous adverse events in the brain of $\mathrm{AD}$ patients, mediated by IL-1 family of pro-inflammatory cytokines.

\section{INFLAMMASOME MEDIATED INFLAMMATORY PATHWAYS ASSOCIATED WITH ALZHEIMER'S DISEASE}

Recently, the role of inflammasomes, particularly NLRP3, in oxidative stress-induced neuroinflammation and impaired amyloid metabolism seen in AD brains has been evaluated and recognized (Halle et al., 2008; Marchesi, 2011; Tan et al., 2013). Neuronal injury caused by insoluble $A \beta$ oligomers and fibrils releases DAMPs which are sensed by PRRs (NLR domain) on NALP inflammasomes initiating a chain of events leading to the maturation of proIL- $1 \beta$ and proIL-18 cytokines and release of their active forms as the final event (Halle et al., 2008; Salminen et al., 2009). Moreover, $A \beta$ can interact with neuronal membranes to create ion channels that allow potassium ion $\left(\mathrm{K}^{+}\right)$efflux mediated by ATPase enzyme, activating inflammasomes and in turn secretion of the active IL-1 family of cytokines (Salminen et al., 2009; Tschopp and Schroder, 2010). Reduction in intracellular $\mathrm{K}^{+}$to $90 \mathrm{mM}$ though has been found to be a requirement for the activation of NLRP3 inflammasomes (higher intracellular concentration of $\mathrm{K}^{+}$inhibits activation of inflammasomes) (Petrilli et al., 2007). Some authors however, found impaired activity of $\mathrm{Na}^{+} / \mathrm{K}^{+}$ATPase in AD patients (Hattori et al., 1998) that is required for the active efflux of $\mathrm{K}^{+}$across the cell membranes, 
which therefore raises the question whether efflux of $\mathrm{K}^{+}$is essential for the activation of inflammasomes. ATPase is required to catalyze ATP into ADP and a phosphate ion with the release of energy that activates the purinergic $\mathrm{P} 2 \mathrm{X}_{7}$ receptor. This receptor in turn decreases intracellular $\mathrm{K}^{+}$levels (Perregaux and Gabel, 1994; Solle et al., 2001). Purinergic signaling has also been shown to control the cerebral vascular tone and this has been implicated in learning and memory, locomotor and feeding behavior and sleep (Burnstock, 2013). Nonetheless, diminished activity of $\mathrm{Na}^{+} / \mathrm{K}^{+}$ATPase reduces the gradient of ions across the cell membranes causing an excitotoxic cellular response resulting in neuronal death (Hattori et al., 1998). This causes a release of DAMPs from dead neurons that potentially act as the activators of NLRP3 inflammasome dependent innate immune response (Rubartelli, 2014). It has also been shown that disease-associated extracellular amyloid and unique protein aggregates caused by inappropriate oligomerization or misfolding are sensed by NLRP3 inflammasomes (Masters and O'Neill, 2011), likely as DAMPs within the resident macrophages after engulfment in the brain. Research has also suggested that the brain in $\mathrm{AD}$ is under increased oxidative stress and $A \beta$ peptides generates free radicals that together further enhance neuron degeneration and death (Markesbery, 1997). Mitochondrial ROS released during tissue injury/death could enhance oxidative damage and signal inflammasome activation up-regulating pro-inflammatory cytokine levels in brain (Martinon, 2010; Tschopp and Schroder, 2010; Naik and Dixit, 2011), potentially resulting in neuroinflammation.

Significant pathology and behavioral deficits characteristics of chronic neuroinflammation do not manifest until advanced age. This has been attributed to the capacity of the brain to compensate for the presence of chronic neuroinflammation by regulating the glutamatergic system (Brothers et al., 2013). This suggests that neuroinflammation in itself does not cause AD; however it acts as an initiator, enhancer and sustainer of AD disease during old age which is reinforced by various other etiologies. Since IL-1 cytokines are key contributors of chronic neuroinflammation and associated neurodegenerative diseases, including AD, inflammasomes provide a possible answer for the mechanism of IL-1 action and the ways in which IL-1 activity is regulated during chronic neuroinflammation in old age (Allan et al., 2005).

\section{IMMUNE FACTORS ASSOCIATED WITH THE ACTIVITY OF INFLAMMASOMES}

It has been well established that both TNF- $\alpha$ and IL- $1 \beta$ stimulate each other's secretion and exhibit overlapping and synergistic effects (Akira et al., 1990; Ikejima et al., 1990; Knofler et al., 1997). For instance, while TNF- $\alpha$ enhances migration of leucocytes in inflamed tissue and promotes apoptosis, IL-1 $\beta$ acts as a potent pyrogen and decreases the threshold of pain by inducing the transcription of cyclooxygenase 2 enzyme, thereby enhancing production of prostaglandins $\mathrm{E}_{2}$, which is responsible for pain and fever. This raises a possibility that inflammasomes, which catalyze IL- $1 \beta$ precursors, may stimulate TNF- $\alpha$ secretion through an indirect pathway. Contrary to this, it has recently been reported that inflammasomes may also be activated independently of PRRs, through TNF- $\alpha$ dependent pathways. TNF- $\alpha$ has been shown to trigger the activation of caspase 1 and in turn secretion of IL-1 $\beta$ (Alvarez and Munoz-Fernandez, 2013), suggesting a possible bidirectional cause-effect relationship between inflammasomes and TNF- $\alpha$. Although the precise mechanism for this has not yet been elucidated, this study indicated that TNF- $\alpha$ may potentially substitute for a TLR mediated stimulus required for inflammasome activation. Moreover, recent findings also suggest that TNF- $\alpha$ induces production of IL-33 in keratinocytes (Taniguchi et al., 2013) and regulates expression of IL-18 in dendritic precursor-like cell line KG-1 and cardiomyocytes (Chandrasekar et al., 2003; Koutoulaki et al., 2010), further supporting the hypothesis that TNF- $\alpha$ has a role in inflammasome activation, although this direct relation between TNF$\alpha$, and IL-18 and IL-33 is yet to be established in the brain. Furthermore, other cytokines such as Type I interferon (IFN) gamma have been shown to inhibit caspase-1 cleavage and reduce IL-1 $\beta$ secretion in rodents (Guarda et al., 2011). Conversely, although IFN-gamma does not cause inflammation by activating inflammasomes directly, it has been shown to augment TNF activity (Dinarello, 2000). Although IL6 is a reliable inflammatory marker it may not always be directly involved in inflammasome mediated inflammation as seen in an IL- 6 knock in mouse model (McGeough et al., 2012). Overall, this suggests a complex and intricate immune pathway mediated by various cytokines that may be involved in the activation of inflammasomes in the brain, and resultant neuroinflammation and changes in brain function; however this requires validation through extensive research.

\section{INFLAMMASOME-INDEPENDENT NEUROINFLAMMATION-MEDIATED BRAIN PATHOLOGIES}

TNF- $\alpha$ is another pro-inflammatory cytokine, in addition to IL-1 cytokines, that has been primarily implicated in neuroinflammation. Elevated levels of TNF- $\alpha$ in particular have been shown to cause a reduction in hippocampal volumes through the neurodegenerative TNFR1 pathway (Baune et al., 2012) and can lead to the development of depressive-like behavior (Eyre et al., 2013). Glial cells, microglia, and astrocytes, are the primary immune effector cells and express various cytokines in the CNS (Rothwell et al., 1996; Hanisch, 2002). Though glial cells are neuroprotective, their over expression or sustained stimulation can result in enhanced production of cytokines (e.g., IL-1 $\beta$ and TNF- $\alpha$ ) (Sawada et al., 1989; Dong and Benveniste, 2001; Hanisch, 2002) resulting in severe neuroinflammation, neurodegeneration and subsequent cognitive dysfunction and psychiatric diseases, such as AD.

While levels of both pro-inflammatory and anti-inflammatory cytokines in the peripheral circulation and CNS have been reported to rise during several brain disorders such as depression, schizophrenia and AD (Schwarz et al., 2001), other humoral immune factors, such as mitogen-activated protein kinases (MAPK), $\mathrm{C}$ reactive protein (CRP), the complement system and chemokines have also been reported to modify brain anatomy and functions. MAPKs are specific protein kinases (serine-threonine specific) that elicit pro-inflammatory and immunomodulatory functions (Lee et al., 1994; Dong et al., 2002). Similarly, CRP is an acute phase reactant protein which enhances inflammation and tissue damage by promoting phagocytosis by opsonization (Du Clos, 2000) and activating the complement system (Padilla 
and Perez, 2003). High levels of CRP in the brain have been linked to neuroinflammation and associated cognitive impairment and dementia (Kuo et al., 2005), and AD (McGeer et al., 2000). Researchers have observed upregulation of the complement system in human brain during $\mathrm{AD}$ and other neurodegenerative diseases (McGeer and McGeer, 1995; Yasojima et al., 1999). The complement system consists of distinct plasma proteins that act as opsonins and initiate a series of inflammatory responses (Janeway et al., 2001). Chemokines promote neuroinflammation by attracting leucocytes to the point of inflammation (Proost et al., 1996; Mélik-Parsadaniantz and Rostène, 2008). Neuroinflammation in turn has been implicated for the impairment of brain function (Campbell, 2004; Ownby, 2010; Tansey and Goldberg, 2010).

Further to the role of inflammasomes and humoral immune factors, several cellular immune factors such as granulocytes, monocytes/macrophages, NK cells, and T lymphocytes have also been shown to have a role in the pathophysiology of neuroinflammation (Petersen and Pedersen, 2005, 2006). The role of NK cells in various brain disorders such as depression, AD and PD has been reviewed and validated by some researchers (Poli et al., 2013). Likewise, the exchange of B cells across the BBB has been reported in patients with multiple sclerosis and associated with the development of autoimmunity in the CNS (von Büdingen et al., 2012).

\section{DISCUSSION \\ NEUROINFLAMMATION AND CYTOKINES}

Neuroinflammation is an innate mechanism to ward off any stimuli that may be harmful to the host and has been shown to be mediated by various immune factors, particularly cytokines (Cacquevel et al., 2004) and chemokines (Ubogu et al., 2006). In particular, pro-inflammatory cytokines, such as TNF- $\alpha$ and the IL-1 family of cytokines, are credited for initiating the inflammatory reactions in the brain in response to an adverse stimulus, for continuation of neuroinflammation by attracting leucocytes at the site of inflammation and activating other pro-inflammatory factors, as well as for the anti-inflammatory pathway by enhancing IL-6 production that in turn stimulates production and expression of anti-inflammatory cytokines and immune factors (Cannon, 2000). However, what is more important here is the mechanism for the activation of these proinflammatory cytokines in response to an adverse stimulus in the first instance. While the concept of an increase in concentration of pro-inflammatory cytokines within the brain during aging and infection is now established, less is known about the mechanisms of cell signaling that result in the pro-inflammatory cytokine gradients within the brain.

\section{NLRP INFLAMMASOMES IN NEUROINFLAMMATION}

While several theories have been postulated to explain this mechanism, recent findings suggest the role of inflammasomes to be important in particular for the IL-1 family of cytokines (Martinon and Tschopp, 2006; Stutz et al., 2009; Schroder and Tschopp, 2010). In response to PAMPs and DAMPs, trans-membranous TLRs that are present in semantic cells such as macrophages and dendritic cells, interact with NLRs on inflammasomes to recognize the stimulus, initiating an inflammasome cascade leading to the release of caspase 1 enzyme in the cytoplasm. Caspase 1 cleaves the pro-forms of the IL-1 family of cytokines to form their active forms (Inohara et al., 2005; Kanneganti et al., 2007; Franchi et al., 2009) that may result in neuroinflammation as a result of increased pro-inflammatory cytokine gradients. Although the acute neuroinflammatory response includes activation of resident tissue macrophages in the CNS and subsequent release of various cytokines and chemokines, this may also cause oxidative and nitrosative stress, which is a first line preventative mechanism against pathogenic extrinsic and intrinsic proteins and is less likely to cause long term damage to neurons (Frank-Cannon et al., 2009). However, it could still result in neurodegenerative changes, as well as in short-term cognitive impairment and exacerbated sickness behavior, as seen in rodent trials after LPSinduced acute neuroinflammation characterized by heightened pro-inflammatory cytokine response (Morimoto et al., 2002; Huang et al., 2008). Nevertheless, a bigger danger is posed by chronic neuroinflammation that is generally seen during old age (Sparkman and Johnson, 2008) and responsible for some brain pathologies such as depression (Wager-Smith and Markou, 2011), AD (Hauss-Wegrzyniak et al., 1998), PD (Tansey and Goldberg, 2010), and multiple sclerosis (Frischer et al., 2009).

For a chronic neuroinflammation to be sustained, the stimuli need to be continuous, potent and self-replicating. This could be explained from the findings that $\mathrm{AD}$ patients in old age suffer from a persistent degenerative condition that involves consistent increases in the various proposed etiologies, be it $\mathrm{A} \beta$ oligomerization or Tau phosphorylation, in the presence of neuroinflammation (Meraz-Ríos et al., 2013). A similar scenario could be plausible in the case of PD where formation of $\alpha$ synuclein fibril aggregate increases in the presence of neuroinflammation. Accelerated formation of the mutant $\alpha$-synuclein fibrils has been linked with the onset of PD (Conway et al., 1998, 2000). Although it has been shown that aggregated $\alpha$ synuclein in microglia-like cells potentially activate the assembly of NLRP3 inflammasomes by inducing vesicle rupture in THP-1 cells that are sensed as danger signals (Cedillos, 2013), the opposite scenario still need to be studied (Cedillos, 2013). Consistent findings have also established the link between various etiologies of depression and neuroinflammation (Maes et al., 1997; Howren et al., 2009; Dowlati et al., 2010; Hannestad et al., 2011).

\section{A SHORT NOTE ON THE ROLE OF INFLAMMASOME MEDIATED NEUROINFLAMMATORY PATHWAYS IN THE COMORBIDITY OF SYSTEMIC ILLNESSES AND PSYCHIATRIC DISORDERS}

High incidences of chronic inflammatory diseases such as cancer (Il'yasova et al., 2005), diabetes (De Rekeneire et al., 2006), osteoarthritis (Stannus et al., 2013), and cardiovascular disease (Volpato et al., 2001) have been demonstrated by prospective and correlative studies in aged cohorts. Investigation at the molecular level suggests increased levels of systemic pro-inflammatory cytokine IL- $1 \beta$, in addition to TNF- $\alpha$ and IL- 6 , and acute phase proteins (e.g., CRP). Moreover, significant findings have confirmed an association between age related depression and level of pro-inflammatory cytokines in the brain (Godbout et al., 
2008). This suggests a mechanism whereby pro-inflammatory cytokines migrate from systemic circulation to the brain and vice versa, especially during old age. Indeed, the pathways for the transport of pro-inflammatory cytokines to brain from systemic circulation have been described in a review by Capuron and Miller (2011) (See Figure 4). Rodent studies have shown increased production and expression of IL-1 $\beta$ in the brain after LPS-induced systemic inflammation (Cunningham et al., 2005) and changes in mood and behavior similar to depression after systemic administration of pro-inflammatory cytokines (Pollak and Yirmiya, 2002). This transport of pro-inflammatory cytokines into the brain and increase in their expression could be the reason for the comorbidity of systemic illnesses with psychiatric disorders in old age. Comorbid conditions, such as Type II diabetes (Grant and Dixit, 2013; Lee et al., 2013), obesity (Stienstra et al., 2011), cardiovascular diseases (Connat, 2011), and cancer (Fallowfield et al., 2001) with psychiatric illnesses therefore supports the hypothesis that inflammasomes play a large role in immunosenescence associated with aging and formation of psychiatric and systemic illnesses with age, the top-most reasons for deaths worldwide as mentioned by World Health Organization (2014). However, future research into the role of inflammasomes in these pathways during aging could possibly explain the link between age-related psychiatric and systemic illnesses.

The above mentioned link between systemic inflammatory conditions and CNS neurological disorders via activation of inflammasomes provides a molecular platform on which to develop therapies to prevent the initiation of those proinflammatory chronic cascades which are detrimental to the CNS. However, although hypothesized a number of times, it is yet to be seen if these therapies can be used to treat diseases such as cancer, diabetes, CVD, and auto-inflammatory disorders (Wilson and Cassel, 2010) that are major killers worldwide and comorbid with brain disorders. Inflammasomes, a molecular platform, could therefore be regarded as an advent to the innovation of therapies in the near future.

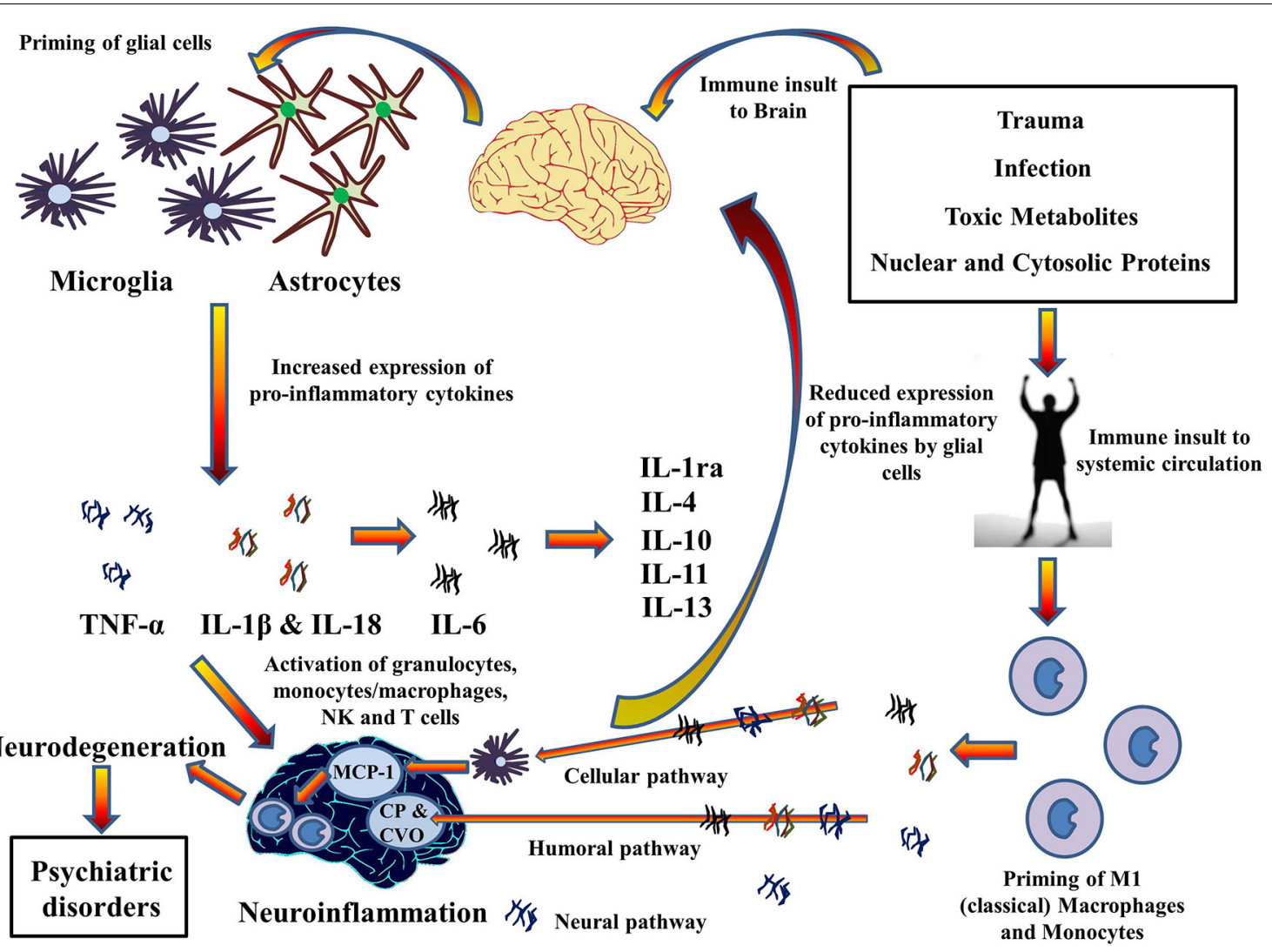

FIGURE 4 | Cytokines hypothesis of neuroinflammation: Implications in comorbidity of systemic illnesses with psychiatric disorders. Pro-inflammatory cytokines can migrate between systemic circulation and brain in both directions which could explain the comorbidity of systemic illnesses with psychiatric disorders. There are three pathways for the transport of pro-inflammatory cytokines from systemic circulation to brain as described by Capuron and Miller (2011): Cellular, Humoral, and Neural.

Moreover, PAMPs and DAMPs from trauma, infection, and metabolic waste can prime glial cells to express pro-inflammatory cytokines TNF- $\alpha, I L-1 \beta$, and
IL-6. When expressed, these cytokines activates granulocytes, monocytes/macrophages, Natural Killer, and T cells and together contribute to the pathophysiology of neuroinflammation. Chronic neuroinflammation could result in neurodegeneration and associated psychiatric disorders. These pro-inflammatory cytokines also stimulate production and expression of anti-inflammatory cytokine by glial cells that function as negative feedback to reduce the expression of pro-inflammatory cytokines, subsiding the neuroinflammation. MCP-1, Monocyte chemoattractant protein-1; CP, Choroid plexus; CVO, Circumventricular organ. 


\section{CONCLUDING REMARKS}

Taken together, it is clear that the discovery of the role of inflammasomes in neuroinflammation has opened an array of research opportunities to investigate the inflammasome targeted therapies for age-related and pathological changes in the brain. It is also clear from the above discussion that the inflammasome activation pathway is complex and may involve the role of other immune factors such as cytokines, as well as mutant protein aggregates such as $A \beta$ and $\alpha$-synuclein fibrils. However, further research into these mechanisms and inflammasome-targeted therapies is advisable for constructing and assessing the complete profile of inflammasome-driven inflammatory pathways in brain.

\section{REFERENCES}

Agostinho, P. A., Cunha, R., and Oliveira, C. (2010). Neuroinflammation, oxidative stress and the pathogenesis of Alzheimer's disease. Curr. Pharm. Des. 16, 2766-2778. doi: 10.2174/138161210793176572

Aizenstein, H. J., Nebes, R. D., Saxton, J. A., Price, J. C., Mathis, C. A., Tsopelas, N. D., et al. (2008). Frequent amyloid deposition without significant cognitive impairment among the elderly. Arch. Neurol. 65, 1509-1517. doi: 10.1001/archneur.65.11.1509

Akira, S., Hirano, T., Taga, T., and Kishimoto, T. (1990). Biology of multifunctional cytokines: IL 6 and related molecules (IL 1 and TNF). FASEB J. 4, 2860-2867.

Alcocer-Gómez, E., de Miguel, M., Casas-Barquero, N., Núñez-Vasco, J., SánchezAlcazar, J. A., Fernández-Rodríguez, A., et al. (2014). NLRP3 inflammasome is activated in mononuclear blood cells from patients with major depressive disorder. Brain Behav. Immun. 36, 111-117. doi: 10.1016/j.bbi.2013.10.017

Allan, S. M., Tyrrell, P. J., and Rothwell, N. J. (2005). Interleukin-1 and neuronal injury. Nat. Rev. Immunol. 5, 629-640. doi: 10.1038/nri1664

Alvarez, S., and Munoz-Fernandez, M. A. (2013). TNF-Alpha may mediate inflammasome activation in the absence of bacterial infection in more than one way. PLoS ONE 8:e71477. doi: 10.1371/journal.pone.0071477

Arend, W. P., Palmer, G., and Gabay, C. (2008). IL-1, IL-18, and IL-33 families of cytokines. Immunol. Rev. 223, 20-38. doi: 10.1111/j.1600-065X.2008. 00624.x

Avila, J., Lucas, J. J., Perez, M., and Hernandez, F. (2004). Role of tau protein in both physiological and pathological conditions. Physiol. Rev. 84, 361-384. doi: 10.1152/physrev.00024.2003

Aw, D., Silva, A. B., and Palmer, D. B. (2007). Immunosenescence: emerging challenges for an ageing population. Immunology 120, 435-446. doi: 10.1111/j.13652567.2007.02555.x

Babic, T. (1999). The cholinergic hypothesis of Alzheimer's disease: a review of progress. J. Neurol. Neurosurg. Psychiatry 67:558. doi: 10.1136/jnnp.67.4.558

Ballatore, C., Lee, V. M.-Y., and Trojanowski, J. Q. (2007). Tau-mediated neurodegeneration in Alzheimer's disease and related disorders. Nat. Rev. Neurosci. 8, 663-672. doi: 10.1038/nrn2194

Barksby, H., Lea, S., Preshaw, P., and Taylor, J. (2007). The expanding family of interleukin -1 cytokines and their role in destructive inflammatory disorders. Clin. Exp. Immunol. 149, 217-225. doi: 10.1111/j.1365-2249.2007.03441.x

Baune, B. T., Konrad, C., Grotegerd, D., Suslow, T., Ohrmann, P., Bauer, J., et al. (2012). Tumor necrosis factor gene variation predicts hippocampus volume in healthy individuals. Biol. Psychiatry 72, 655-662. doi: 10.1016/j.biopsych.2012. 04.002

Belmaker, R., and Agam, G. (2008). Major depressive disorder. N. Engl. J. Med. 358, 55-68. doi: 10.1056/NEJMra073096

Bertram, L., and Tanzi, R. E. (2009). Genome-wide association studies in Alzheimer's disease. Hum. Mol. Genet. 18, R137-R45. doi: 10.1093/hmg/ddp406

Biesmans, S., Meert, T. F., Bouwknecht, J. A., Acton, P. D., Davoodi, N., De Haes, P., et al. (2013). Systemic immune activation leads to neuroinflammation and sickness behavior in mice. Mediators Inflamm. 2013:271359. doi: 10.1155/2013/ 271359

Brothers, H. M., Bardou, I., Hopp, S. C., Marchalant, Y., Kaercher, R. M., Turner, S. M., et al. (2013). Time-dependent compensatory responses to chronic neuroinflammation in hippocampus and brainstem: the potential role of glutamate neurotransmission. J. Alzheimers Dis. Parkinsonism. 3:110. doi: 10.4172/21610460.1000110
Burnstock, G. (2013). "Introduction to purinergic signalling in the brain," in Glioma Signaling ed J. Barańska (Netherlands: Springer), 1-12. doi: 10.1007/978-94-007-4719-7_1

Cacquevel, M., Lebeurrier, N., Cheenne, S., and Vivien, D. (2004). Cytokines in neuroinflammation and Alzheimer's disease. Curr. Drug Targets 5, 529-534. doi: $10.2174 / 1389450043345308$

Campbell, A. (2004). Inflammation, neurodegenerative diseases, and environmental exposures. Ann. N.Y. Acad. Sci. 1035, 117-132. doi: 10.1196/annals.1332.008

Cannon, J. G. (2000). Inflammatory cytokines in nonpathological states. Physiology $15,298-303$.

Capuron, L., and Miller, A. H. (2011). Immune system to brain signaling: neuropsychopharmacological implications. Pharmacol. Ther. 130, 226-238. doi: 10.1016/j.pharmthera.2011.01.014

Cedillos, R. O. (2013). Alpha-Synuclein Aggregates Activate the Nlrp3 Inflammasome Following Vesicle Rupture. Master's Theses, Paper 1859. Available online at: http://ecommons.luc.edu/luc_theses/1859

Chakraborty, S., Kaushik, D. K., Gupta, M., and Basu, A. (2010). Inflammasome signaling at the heart of central nervous system pathology. J. Neurosci. Res. 88, 1615-1631. doi: 10.1002/jnr.22343

Chandrasekar, B., Colston, J. T., de la Rosa, S. D., Rao, P. P., and Freeman, G. L. (2003). TNF-alpha and H2O2 induce IL-18 and IL-18R beta expression in cardiomyocytes via NF-kappa B activation. Biochem. Biophys. Res. Commun. 303 1152-1158. doi: 10.1016/S0006-291X(03)00496-0

Conde, J. R., and Streit, W. J. (2006). Microglia in the aging brain. J. Neuropathol. Exp. Neurol. 65, 199-203. doi: 10.1097/01.jnen.0000202887.22082.63

Connat, J. L. (2011). Inflammasome and cardiovascular diseases. Br. J. Cancer 60, 48-54. doi: 10.1016/j.ancard.2010.07.011

Conway, K. A., Harper, J. D., and Lansbury, P. T. (1998). Accelerated in vitro fibril formation by a mutant $\alpha$-synuclein linked to early-onset Parkinson disease. Nat. Med. 4, 1318-1320. doi: 10.1038/3311

Conway, K. A., Harper, J. D., and Lansbury, P. T. (2000). Fibrils formed in vitro from $\alpha$-synuclein and two mutant forms linked to Parkinson's disease are typical amyloid. Biochemistry 39, 2552-2563. doi: 10.1021/bi991447r

Cribbs, D. H., Berchtold, N. C., Perreau, V., Coleman, P. D., Rogers, J., Tenner, A. J., et al. (2012). Extensive innate immune gene activation accompanies brain aging, increasing vulnerability to cognitive decline and neurodegeneration: a microarray study. J. Neuroinflammation 9:179. doi: 10.1186/1742-2094-9-179

Cunningham, C., Wilcockson, D. C., Campion, S., Lunnon, K., and Perry, V. H. (2005). Central and systemic endotoxin challenges exacerbate the local inflammatory response and increase neuronal death during chronic neurodegeneration. J. Neurosci. 25, 9275-9284. doi: 10.1523/JNEUROSCI.261405.2005

Davis, B. K., Wen, H., and Ting, J. P. (2011). The inflammasome NLRs in immunity, inflammation, and associated diseases. Annu. Rev. Immunol. 29, 707-735. doi: 10.1146/annurev-immunol-031210-101405

De Rekeneire, N., Peila, R., Ding, J., Colbert, L. H., Visser, M., Shorr, R. I., et al. (2006). Diabetes, hyperglycemia, and inflammation in older individuals the health, aging and body composition study. Diabetes Care 29, 1902-1908. doi: $10.2337 / \mathrm{dc} 05-2327$

Dilger, R. N., and Johnson, R. W. (2008). Aging, microglial cell priming, and the discordant central inflammatory response to signals from the peripheral immune system. J. Leukoc. Biol. 84, 932-939. doi: 10.1189/jlb.0208108

Dinarello, C. A. (2000). Proinflammatory cytokines. CHEST J. 118, 503-508. doi: 10.1378/chest.118.2.503

Dinarello, C. A. (2009). Immunological and inflammatory functions of the interleukin-1 family. Annu. Rev. Immunol. 27, 519-550. doi: 10.1146/annurev. immunol.021908.132612

Dong, C., Davis, R. J., and Flavell, R. A. (2002). MAP kinases in the immune response. Annu. Rev. Immunol. 20, 55-72. doi: 10.1146/annurev.immunol.20. 091301.131133

Dong, Y., and Benveniste, E. N. (2001). Immune function of astrocytes. Glia 36, 180-190. doi: 10.1002/glia.1107

Dowlati, Y., Herrmann, N., Swardfager, W., Liu, H., Sham, L., Reim, E. K., et al. (2010). A meta-analysis of cytokines in major depression. Biol. Psychiatry 67, 446-457. doi: 10.1016/j.biopsych.2009.09.033

Du Clos, T. W. (2000). Function of C-reactive protein. Ann. Med. 32, 274-278. doi: $10.3109 / 07853890009011772$

Eyre, H., and Baune, B. T. (2012). Neuroimmunological effects of physical exercise in depression. Brain Behav. Immun. 26, 251-266. doi: 10.1016/j.bbi.2011.09.015 
Eyre, H., Papps, E., and Baune, B. T. (2013). Treating depression and depressionlike behavior with physical activity: an immune perspective. Front. Psychiatry 4:3. doi: 10.3389/fpsyt.2013.00003

Fallowfield, L., Ratcliffe, D., Jenkins, V., and Saul, J. (2001). Psychiatric morbidity and its recognition by doctors in patients with cancer. Br. J. Cancer 84:1011. doi: 10.1054/bjoc.2001.1724

Farooq, R. K., Isingrini, E., Tanti, A., Le Guisquet, A.-M., Arlicot, N., Minier, F., et al. (2012). Is unpredictable chronic mild stress (UCMS) a reliable model to study depression-induced neuroinflammation? Behav. Brain Res. 231, 130-137. doi: 10.1016/j.bbr.2012.03.020.

Felderhoff-Mueser, U., Schmidt, O. I., Oberholzer, A., Bührer, C., and Stahel, P. F. (2005). IL-18: a key player in neuroinflammation and neurodegeneration? Trends Neurosci. 28, 487-493. 10.1016/j.tins.2005.06.008

Fischer, A., Otte, C., Krieger, T., Nicholls, R. A., Krüger, S., Ziegler, K. J., et al. (2012). Decreased hydrocortisone sensitivity of $\mathrm{T}$ cell function in multiple sclerosis-associated major depression. Psychoneuroendocrinology 37, 1712-1718. doi: 10.1016/j.psyneuen.2012.03.001

Franchi, L., Warner, N., Viani, K., and Nuñez, G. (2009). Function of Nod-like receptors in microbial recognition and host defense. Immunol. Rev. 227, 106-128. doi: 10.1111/j.1600-065X.2008.00734.x.

Frank-Cannon, T. C., Alto, L. T., McAlpine, F. E., and Tansey, M. G. (2009). Does neuroinflammation fan the flame in neurodegenerative diseases. Mol. Neurodegener. 4, 1-13. doi: 10.1186/1750-1326-4-47

Frischer, J. M., Bramow, S., Dal-Bianco, A., Lucchinetti, C. F., Rauschka, H., Schmidbauer, M., et al. (2009). The relation between inflammation and neurodegeneration in multiple sclerosis brains. Brain 132, 1175-1189. doi: 10.1093/ brain/awp070

Frohman, E. M., Racke, M. K., and Raine, C. S. (2006). Multiple sclerosisthe plaque and its pathogenesis. N. Engl. J. Med. 354, 942-955. doi: 10.1056/NEJMra052130

Garg, N. J. (2011). Inflammasomes in cardiovascular diseases. Am. J. Cardiovasc. Dis. 1:244.

Godbout, J., Chen, J., Abraham, J., Richwine, A., Berg, B., Kelley, K., et al. (2005). Exaggerated neuroinflammation and sickness behavior in aged mice following activation of the peripheral innate immune system. FASEB J. 19, 1329-1331. doi: 10.1096/fj.05-3776fje

Godbout, J. P., and Johnson, R. W. (2009). Age and neuroinflammation: a lifetime of psychoneuroimmune consequences. Immunol. Allergy Clin. North Am. 29, 321-337. doi: 10.1016/j.iac.2009.02.007

Godbout, J. P., Moreau, M., Lestage, J., Chen, J., Sparkman, N. L., O’Connor, J., et al. (2008). Aging exacerbates depressive-like behavior in mice in response to activation of the peripheral innate immune system. Neuropsychopharmacology 33, 2341-2351. doi: 10.1038/sj.npp.1301649

Grant, R. W., and Dixit, V. D. (2013). Mechanisms of disease: inflammasome activation and the development of type 2 diabetes. Front. Immunol. 4:50. doi: 10.3389/fimmu.2013.00050

Gris, D., Ye, Z., Iocca, H. A., Wen, H., Craven, R. R., Gris, P., et al. (2010). NLRP3 plays a critical role in the development of experimental autoimmune encephalomyelitis by mediating Th1 and Th17 responses. J. Immunol. 185, 974-981. doi: 10.4049/jimmunol.0904145

Guarda, G., Braun, M., Staehli, F., Tardivel, A., Mattmann, C., Forster, I., et al. (2011). Type I interferon inhibits interleukin-1 production and inflammasome activation. Immunity 34, 213-223. doi: 10.1016/j.immuni.2011.02.006

Halle, A., Hornung, V., Petzold, G. C., Stewart, C. R., Monks, B. G., Reinheckel, T., et al. (2008). The NALP3 inflammasome is involved in the innate immune response to amyloid- $\beta$. Nat. Immunol. 9, 857-865. doi: 10.1038/ni.1636

Hanisch, U. K. (2002). Microglia as a source and target of cytokines. Glia 40, 140-155. doi: 10.1002/glia.10161

Hannestad, J., DellaGioia, N., and Bloch, M. (2011). The effect of antidepressant medication treatment on serum levels of inflammatory cytokines: a meta-analysis. Neuropsychopharmacology 36, 2452-2459. doi: 10.1038/npp. 2011.132

Hattori, N., Kitagawa, K., Higashida, T., Yagyu, K., Shimohama, S., Wataya, T., et al. (1998). Cl-ATPase and $\mathrm{Na}+/ \mathrm{K}+$-ATPase activities in Alzheimer's disease brains. Neurosci. Lett. 254, 141-144. doi: 10.1016/S0304-3940(98)00654-5

Hauss-Wegrzyniak, B., Dobrzanski, P., Stoehr, J. D., and Wenk, G. L. (1998). Chronic neuroinflammation in rats reproduces components of the neurobiology of Alzheimer's disease. Brain Res. 780, 294-303. doi: 10.1016/S00068993(97)01215-8
Hein, A. M., and O'Banion, M. K. (2009). Neuroinflammation and memory: the role of prostaglandins. Mol. Neurobiol. 40, 15-32. doi: 10.1007/s12035-0098066-z

Heneka, M. T., O'Banion, M. K., Terwel, D., and Kummer, M. P. (2010). Neuroinflammatory processes in Alzheimer's disease. J. Neural Transm. 117, 919-947. doi: 10.1007/s00702-010-0438-z

Hirsch, E. C., Vyas, S., and Hunot, S. (2012). Neuroinflammation in Parkinson's disease. Parkinsonism Relat. Disord. 18, S210-S212. doi: 10.1016/S13538020(11)70065-7

Hohmann, H., Bechter, K., and Schneider, E. (2014). A small and validated cytokine panel supports inflammasome activation in cerebrospinal fluid of patients with major depression and schizophrenia. Neurol. Psychiatry Brain Res. 20, 13-14. doi: 10.1016/j.npbr.2014.01.153

Howren, M. B., Lamkin, D. M., and Suls, J. (2009). Associations of depression with C-reactive protein, IL-1, and IL-6: a meta-analysis. Psychosom. Med. 71, 171-186. doi: 10.1097/PSY.0b013e3181907c1b

Huang, Y., Henry, C., Dantzer, R., Johnson, R., and Godbout, J. (2008). Exaggerated sickness behavior and brain proinflammatory cytokine expression in aged mice in response to intracerebroventricular lipopolysaccharide. Neurobiol. Aging 29, 1744-1753. doi: 10.1016/j.neurobiolaging.2007.04.012

Ikejima, T., Okusawa, S., Ghezzi, P., Van Der Meer, J. W., and Dinarello, C. A. (1990). Interleukin-l induces tumor necrosis factor (TNF) in human peripheral blood mononuclear cells in vitro and a circulating TNF-Iike activity in rabbits. J. Infect. Dis. 162, 215-223. doi: 10.1093/infdis/162.1.215

Il'yasova, D., Colbert, L. H., Harris, T. B., Newman, A. B., Bauer, D. C., Satterfield, S., et al. (2005). Circulating levels of inflammatory markers and cancer risk in the health aging and body composition cohort. Cancer Epidemiol. Biomarkers Prev. 14, 2413-2418. doi: 10.1158/1055-9965.EPI-05-0316

Inohara, N., Chamaillard, M., McDonald, C., and Nunez, G. (2005). NOD-LRR proteins: role in host-microbial interactions and inflammatory disease. Annu. Rev. Biochem. 74, 355-383. doi: 10.1146/annurev.biochem.74.082803.133347

Iwata, M., Ota, K. T., and Duman, R. S. (2013). The inflammasome: pathways linking psychological stress, depression, and systemic illnesses. Brain Behav. Immun. 31, 105-114. doi: 10.1016/j.bbi.2012.12.008

Janeway, C. A., Travers, P., Walport, M., and Shlomchik, M. (2001). "The complement system and innate immunity," in Immunobiology: the Immune System in Health and Disease, 5th edn (New York, NY: Garland), 43-64

Kamboh, M., Demirci, F., Wang, X., Minster, R., Carrasquillo, M., Pankratz, V., et al. (2012). Genome-wide association study of Alzheimer's disease. Transl. Psychiatry 2:e117. doi: 10.1007/s11910-013-0381-0

Kanneganti, T.-D., Lamkanfi, M., and Núñez, G. (2007). Intracellular NODlike receptors in host defense and disease. Immunity 27, 549-559. doi: 10.1016/j.immuni.2007.10.002

Kim, J., Ahn, H., Han, B. C., Lee, S. H., Cho, Y. W., Kim, C. H., et al. (2014). Korean red ginseng extracts inhibit NLRP3 and AIM2 inflammasome activation. Immunol. Lett. 158, 143-150. doi: 10.1016/j.imlet.2013.12.017

Kitazawa, M., Oddo, S., Yamasaki, T. R., Green, K. N., and LaFerla, F. M. (2005). Lipopolysaccharide-induced inflammation exacerbates tau pathology by a cyclin-dependent kinase 5-mediated pathway in a transgenic model of Alzheimer's disease. J. Neurosci. 25, 8843-8853. doi: 10.1523/JNEUROSCI. 2868-05.2005

Knofler, M., Kiss, H., Mosl, B., Egarter, C., and Husslein, P. (1997). Interleukin1 stimulates tumor necrosis factor-alpha (TNF-alpha) release from cytotrophoblastic BeWo cells independently of induction of the TNF-alpha mRNA. FEBS Lett. 405, 213-218. doi: 10.1016/S0014-5793(97)00190-7

Koutoulaki, A., Langley, M., Sloan, A. J., Aeschlimann, D., and Wei, X.-Q. (2010). TNF $\alpha$ and TGF- $\beta 1$ influence IL-18-induced IFN $\gamma$ production through regulation of IL-18 receptor and T-bet expression. Cytokine 49, 177-184. doi: 10.1016/j.cyto.2009.09.015

Kumar, H., Kawai, T., and Akira, S. (2009). Toll-like receptors and innate immunity. Biochem. Biophys. Res. Commun. 388, 621-625. doi: 10.1016/j.bbrc.2009. 08.062

Kuo, H.-K., Yen, C.-J., Chang, C.-H., Kuo, C.-K., Chen, J.-H., and Sorond, F. (2005). Relation of C-reactive protein to stroke, cognitive disorders, and depression in the general population: systematic review and meta-analysis. Lancet Neurol. 4, 371-380. doi: 10.1016/S1474-4422(05)70099-5

Lee, H. M., Kim, J. J., Kim, H. J., Shong, M., Ku, B. J., and Jo, E. K. (2013). Upregulated NLRP3 inflammasome activation in patients with type 2 diabetes. Diabetes 62, 194-204. doi: 10.2337/db12-0420 
Lee, H.-G., Perry, G., Moreira, P. I., Garrett, M. R., Liu, Q., Zhu, X., et al. (2005). Tau phosphorylation in Alzheimer's disease: pathogen or protector? Trends Mol. Med. 11, 164-169. doi: 10.1016/j.molmed.2005.02.008

Lee, J. C., Laydon, J. T., McDonnell, P. C., Gallagher, T. F., Kumar, S., Green, D., et al. (1994). A protein kinase involved in the regulation of inflammatory cytokine biosynthesis. Nature 372, 739-746. doi: 10.1038/372739a0

Lee, J. W., Lee, Y. K., Yuk, D. Y., Choi, D. Y., Ban, S. B., Oh, K. W., et al. (2008). Neuro-inflammation induced by lipopolysaccharide causes cognitive impairment through enhancement of beta-amyloid generation. J. Neuroinflammation 5:37. doi: 10.1186/1742-2094-5-37

Liberati, A., Altman, D. G., Tetzlaff, J., Mulrow, C., Gøtzsche, P. C., Ioannidis, J. P., et al. (2009). The PRISMA statement for reporting systematic reviews and meta-analyses of studies that evaluate health care interventions: explanation and elaboration. Ann. Intern. Med. 151, W-65-W-94. doi: 10.7326/0003-4819-1514-200908180-00136

Licastro, F., Pedrini, S., Caputo, L., Annoni, G., Davis, L. J., Ferri, C., et al. (2000). Increased plasma levels of interleukin-1, interleukin-6 and $\alpha-1$ antichymotrypsin in patients with Alzheimer's disease: peripheral inflammation or signals from the brain? J. Neuroimmunol. 103, 97-102. doi: 10.1016/S01655728(99)00226-X

Liew, F. Y., Pitman, N. I., and McInnes, I. B. (2010). Disease-associated functions of IL-33: the new kid in the IL-1 family. Nat. Rev. Immunol. 10, 103-110. doi: $10.1038 /$ nri2692

Liu, L., and Chan, C. (2014). The role of inflammasome in Alzheimer's disease. Ageing Res. Rev. 15, 6-15. doi: 10.1016/j.arr.2013.12.007

Maes, M., Bosmans, E., De Jongh, R., Kenis, G., Vandoolaeghe, E., and Neels, H. (1997). Increased serum IL-6 and IL-1 receptor antagonist concentrations in major depression and treatment resistant depression. Cytokine 9, 853-858. doi: 10.1006/cyto. 1997.0238

Marchesi, V. T. (2011). Alzheimer's dementia begins as a disease of small blood vessels, damaged by oxidative-induced inflammation and dysregulated amyloid metabolism: implications for early detection and therapy. FASEB J. 25, 5-13. doi: 10.1096/fj.11-0102ufm

Markesbery, W. R. (1997). Oxidative stress hypothesis in Alzheimer's disease. Free Radic. Biol. Med. 23, 134-147. doi: 10.1016/S0891-5849(96)00629-6

Martinon, F. (2010). Signaling by ROS drives inflammasome activation. Eur. J. Immunol. 40, 616-619. doi: 10.1002/eji.200940168

Martinon, F., Burns, K., and Tschopp, J. (2002). The inflammasome: a molecular platform triggering activation of inflammatory caspases and processing of proIL-beta. Mol. Cell 10, 417-426. doi: 10.1016/S1097-2765(02)00599-3

Martinon, F., and Tschopp, J. (2006). Inflammatory caspases and inflammasomes: master switches of inflammation. Cell Death Differ. 14, 10-22. doi: 10.1038/sj.cdd. 4402038

Masters, S. L., and O'Neill, L. A. (2011). Disease-associated amyloid and misfolded protein aggregates activate the inflammasome. Trends Mol. Med. 17, 276-282.

Mawhinney, L. J., de Rivero Vaccari, J. P., Dale, G. A., Keane, R. W., and Bramlett, H. M. (2011). Heightened inflammasome activation is linked to agerelated cognitive impairment in Fischer 344 rats. BMC Neurosci. 12:123. doi: 10.1186/1471-2202-12-123

McAfoose, J., and Baune, B. T. (2009). Evidence for a cytokine model of cognitive function. Neurosci. Biobehav. Rev. 33, 355-366. doi: 10.1016/j.neubiorev.2008. 10.005

McGeer, P. L., and McGeer, E. G. (1995). The inflammatory response system of brain: implications for therapy of Alzheimer and other neurodegenerative diseases. Brain Res. Rev. 21, 195-218. doi: 10.1016/0165-0173(95)00011-9

McGeer, P. L., and McGeer, E. G. (2004). Inflammation and the degenerative diseases of aging. Ann. N.Y. Acad. Sci. 1035, 104-116. doi: 10.1196/annals.1332.007

McGeer, P. L., McGeer, E., and Yasojima, K. (2000). "Alzheimer disease and neuroinflammation," in Advances in Dementia Research eds K. Jellinger, R. Schmidt and M. Windisch (Vienna: Springer), 53-57. doi: 10.1007/978-3-7091-6781-6_8

McGeough, M. D., Pena, C. A., Mueller, J. L., Pociask, D. A., Broderick, L., Hoffman, H. M., et al. (2012). Cutting edge: IL-6 is a marker of inflammation with no direct role in inflammasome-mediated mouse models. J. Immunol. 189, 2707-2711. doi: 10.4049/jimmunol.1101737

Mélik-Parsadaniantz, S., and Rostène, W. (2008). Chemokines and neuromodulation. J. Neuroimmunol. 198, 62-68. doi: 10.1016/j.jneuroim.2008.04.022

Meraz-Ríos, M. A., Toral-Rios, D., Franco-Bocanegra, D., Villeda-Hernández, J., and Campos-Peña, V. (2013). Inflammatory process in Alzheimer's Disease. Front. Integr. Neurosci. 7:59. doi: 10.3389/fnint.2013.00059
Moher, D., Liberati, A., Tetzlaff, J., and Altman, D. G. (2009). Preferred reporting items for systematic reviews and meta-analyses: the PRISMA statement. Ann. Intern. Med. 151, 264-269. doi: 10.7326/0003-4819-151-4-200908180-00135

Möller, T. (2010). Neuroinflammation in Huntington's disease. J. Neural Transm. 117, 1001-1008. doi: 10.1007/s00702-010-0430-7

Moon, M., McCusker, R., Lawson, M., Dantzer, R., and Kelley, K. (2009). Mice lacking the inflammasome component caspase-1 are resistant to central lipopolysaccharide-induced depressive-like behavior. Brain Behav. Immun. 23:S50. doi: 10.1016/j.bbi.2009.06.095

Morimoto, K., Murasugi, T., and Oda, T. (2002). Acute neuroinflammation exacerbates excitotoxicity in rat hippocampus in vivo. Exp. Neurol. 177, 95-104. doi: 10.1006/exnr.2002.7991

Mrak, R. E., and Griffin, W. S. T. (2005). Glia and their cytokines in progression of neurodegeneration. Neurobiol. Aging 26, 349-354. doi: 10.1016/j. neurobiolaging.2004.05.010

Naik, E., and Dixit, V. M. (2011). Mitochondrial reactive oxygen species drive proinflammatory cytokine production. J. Exp. Med. 208, 417-420. doi: 10.1084/jem.20110367

Ownby, R. L. (2010). Neuroinflammation and cognitive aging. Curr. Psychiatry Rep. 12, 39-45. doi: 10.1007/s11920-009-0082-1

Padilla, A. M., and Perez, W. (2003). Acculturation, social identity, and social cognition: a new perspective. Hisp. J. Behav. Sci. 25, 35-55. doi: 10.1177/0739986303 251694

Palop, J. J., and Mucke, L. (2010). Amyloid-[beta]-induced neuronal dysfunction in Alzheimer's disease: from synapses toward neural networks. Nat. Neurosci. 13, 812-818. doi: 10.1038/nn.2583

Perregaux, D., and Gabel, C. A. (1994). Interleukin-1 beta maturation and release in response to ATP and nigericin. Evidence that potassium depletion mediated by these agents is a necessary and common feature of their activity. J. Biol. Chem. 269, 15195-15203.

Petersen, A. M. W., and Pedersen, B. K. (2005). The anti-inflammatory effect of exercise. J. Appl. Physiol. 98, 1154-1162. doi: 10.1152/japplphysiol.00164.2004

Petersen, A. M. W., and Pedersen, B. K. (2006). The role of IL-6 in mediating the anti-inflammatory effects of exercise. J. Physiol. Pharmacol. 57, 43-51.

Petrilli, V., Papin, S., Dostert, C., Mayor, A., Martinon, F., and Tschopp, J. (2007). Activation of the NALP3 inflammasome is triggered by low intracellular potassium concentration. Cell Death Differ. 14, 1583-1589. doi: 10.1038/sj.cdd. 4402195

Petrilli, V., Papin, S., and Tschopp, J. (2005). The inflammasome. Curr. Biol. 15:R581. doi: 10.1016/j.cub.2005.07.049

Pimplikar, S. W. (2014). Neuroinflammation in Alzheimer's disease: from pathogenesis to a therapeutic target. J. Clin. Immunol. 34, S64-S69. doi: 10.1007/ s10875-014-0032-5

Poli, A., Kmiecik, J., Domingues, O., Hentges, F., Bléry, M., Chekenya, M., et al. (2013). NK cells in central nervous system disorders. J. Immunol. 190, 5355-5362. doi: 10.4049/jimmunol.1203401

Pollak, Y., and Yirmiya, R. (2002). Cytokine-induced changes in mood and behaviour: implications for "depression due to a general medical condition", immunotherapy and antidepressive treatment. Int. J. Neuropsychopharmacol. 5, 389-399. doi: 10.1017/S1461145702003152

Proost, P., Wuyts, A., and Van Damme, J. (1996). The role of chemokines in inflammation. Int. J. Clin. Lab. Res. 26, 211-223. doi: 10.1007/BF02602952

Rothwell, N. J., Luheshi, G., and Toulmond, S. (1996). Cytokines and their receptors in the central nervous system: physiology, pharmacology, and pathology. Pharmacol. Ther. 69, 85-95. doi: 10.1016/0163-7258(95)02033-0

Rozovsky, I., Finch, C., and Morgan, T. (1998). Age-related activation of microglia and astrocytes: in vitro studies show persistent phenotypes of aging, increased proliferation, and resistance to down-regulation. Neurobiol. Aging 19, 97-103. doi: 10.1016/S0197-4580(97)00169-3

Rubartelli, A. (2014). DAMP-mediated activation of NLRP3-inflammasome in brain sterile inflammation: the fine line between healing and neurodegeneration. Front. Immunol. 5:99. doi: 10.3389/fimmu.2014.00099

Rubio-Perez, J. M., and Morillas-Ruiz, J. M. (2012). A review: inflammatory process in Alzheimer's disease, role of cytokines. ScientificWorldJournal 2012:756357. doi: 10.1100/2012/756357

Salminen, A., Ojala, J., Kaarniranta, K., and Kauppinen, A. (2012). Mitochondrial dysfunction and oxidative stress activate inflammasomes: impact on the aging process and age-related diseases. Cell. Mol. Life Sci. 69, 2999-3013. doi: 10.1007/s00018-012-0962-0 
Salminen, A., Ojala, J., Kauppinen, A., Kaarniranta, K., and Suuronen, T. (2009). Inflammation in Alzheimer's disease: amyloid- $\beta$ oligomers trigger innate immunity defence via pattern recognition receptors. Progr. Neurobiol. 87, 181-194. doi: 10.1016/j.pneurobio.2009.01.001

Sawada, M., Kondo, N., Suzumura, A., and Marunouchi, T. (1989). Production of tumor necrosis factor-alpha by microglia and astrocytes in culture. Brain Res. 491, 394-397. doi: 10.1016/0006-8993(89)90078-4

Schroder, K., and Tschopp, J. (2010). The inflammasomes. Cell 140, 821-832. doi: 10.1016/j.cell.2010.01.040

Schwarz, M. J., Chiang, S., Müller, N., and Ackenheil, M. (2001). T-helper-1 and Thelper-2 responses in psychiatric disorders. Brain Behav. Immun. 15, 340-370. doi: 10.1006/brbi.2001.0647

Senchina, D. S., and Kohut, M. L. (2007). Immunological outcomes of exercise in older adults. Clin. Interv. Aging 2:3. doi: 10.2147/ciia.2007.2.1.3

Sheng, J. G., Bora, S. H., Xu, G., Borchelt, D. R., Price, D. L., and Koliatsos, V. E. (2003). Lipopolysaccharide-induced-neuroinflammation increases intracellular accumulation of amyloid precursor protein and amyloid $\beta$ peptide in APPswe transgenic mice. Neurobiol. Dis. 14, 133-145. doi: 10.1016/S09699961(03)00069-X

Shinkai, S., Konishi, M., and Shephard, R. J. (1998). Aging and immune response to exercise. Can. J. Physiol. Pharmacol. 76, 562-572. doi: 10.1139/y98-043

Simi, A., Lerouet, D., Pinteaux, E., and Brough, D. (2007). Mechanisms of regulation for interleukin- $\beta$ in neurodegenerative disease. Neuropharmacology 52, 1563-1569. doi: 10.1016/j.neuropharm.2007.02.011

Sims, J. E., and Smith, D. E. (2010). The IL-1 family: regulators of immunity. Nat. Rev. Immunol. 10, 89-102. doi: 10.1038/nri2691

Solle, M., Labasi, J., Perregaux, D. G., Stam, E., Petrushova, N., Koller, B. H., et al. (2001). Altered cytokine production in mice lacking P2X7Receptors. J. Biol. Chem. 276, 125-132. doi: 10.1074/jbc.M006781200

Sparkman, N. L., and Johnson, R. W. (2008). Neuroinflammation associated with aging sensitizes the brain to the effects of infection or stress. Neuroimmunomodulation 15, 323-330. doi: 10.1159/000156474

Stannus, O. P., Jones, G., Blizzard, L., Cicuttini, F. M., and Ding, C. (2013). Associations between serum levels of inflammatory markers and change in knee pain over 5 years in older adults: a prospective cohort study. Ann. Rheum. Dis. 72, 535-540. doi: 10.1136/annrheumdis-2011-201047

Stienstra, R., van Diepen, J. A., Tack, C. J., Zaki, M. H., van de Veerdonk, F. L., Perera, D., et al. (2011). Inflammasome is a central player in the induction of obesity and insulin resistance. Proc. Natl. Acad. Sci. U.S.A. 108, 15324-15329. doi: $10.1073 /$ pnas. 1100255108

Streit, W. J. (2005). Microglia and neuroprotection: implications for Alzheimer's disease. Brain Res. Rev. 48, 234-239. doi: 10.1016/j.brainresrev.2004.12.013

Stutz, A., Golenbock, D. T., and Latz, E. (2009). Inflammasomes: too big to miss. J. Clin. Invest. 119:3502. doi: 10.1172/JCI40599

Sugaya, K., Chouinard, M., Greene, R., Robbins, M., Personett, D., Kent, C., et al. (1996). Molecular indices of neuronal and glial plasticity in the hippocampal formation in a rodent model of age-induced spatial learning impairment. J. Neurosci. 16, 3427-3443.

Tabet, N. (2006). Acetylcholinesterase inhibitors for Alzheimer's disease: antiinflammatories in acetylcholine clothing! Age Ageing 35, 336-338. doi: 10.1093/ ageing/afl027

Tan, M. S., Yu, J. T., Jiang, T., Zhu, X. C., and Tan, L. (2013). The NLRP3 inflammasome in Alzheimer's disease. Mol. Neurobiol. 48, 875-882. doi: 10.1007/s12035013-8475-x

Taniguchi, K., Yamamoto, S., Hitomi, E., Inada, Y., Suyama, Y., Sugioka, T., et al. (2013). Interleukin-33 is induced by tumor necrosis factor-alpha and interferon-gamma in keratinocytes, and contributes to allergic contact dermatitis. J. Investig. Allergol. Clin. Immunol. 23, 428-434.

Tansey, M. G., and Goldberg, M. S. (2010). Neuroinflammation in Parkinson's disease: its role in neuronal death and implications for therapeutic intervention. Neurobiol. Dis. 37, 510-518. doi: 10.1016/j.nbd.2009.11.004

Tarkowski, E., Liljeroth, A. M., Minthon, L., Tarkowski, A., Wallin, A., and Blennow, K. (2003). Cerebral pattern of pro- and anti-inflammatory cytokines in dementias. Brain Res. Bull. 61, 255-260. doi: 10.1016/S0361-9230(03)00088-1

Tha, K. K., Okuma, Y., Miyazaki, H., Murayama, T., Uehara, T., Hatakeyama, R., et al. (2000). Changes in expressions of proinflammatory cytokines IL-1 $\beta$, TNF$\alpha$ and IL-6 in the brain of senescence accelerated mouse (SAM) P8. Brain Res. 885, 25-31. doi: 10.1016/S0006-8993(00)02883-3
Tschopp, J., and Schroder, K. (2010). NLRP3 inflammasome activation: the convergence of multiple signalling pathways on ROS production? Nat. Rev. Immunol. 10, 210-215. doi: 10.1038/nri2725

Ubogu, E. E., Cossoy, M. B., and Ransohoff, R. M. (2006). The expression and function of chemokines involved in CNS inflammation. Trends Pharmacol. Sci. 27, 48-55. doi: 10.1016/j.tips.2005.11.002

van der Staay, F. J. (2002). Assessment of age-associated cognitive deficits in rats: a tricky business. Neurosci. Biobehav. Rev. 26, 753-759. doi: 10.1016/S01497634(02)00062-3

van de Veerdonk, F. L., and Netea, M. G. (2011). "Toll-like receptors and inflammasomes," in The Inflammasomes eds I. Couillin, V. Pétrilli and F. Martinon (Basel: Springer), 123-32. doi: 10.1007/978-3-0348-0148-5_8

Volpato, S., Guralnik, J. M., Ferrucci, L., Balfour, J., Chaves, P., Fried, L. P., et al. (2001). Cardiovascular disease, interleukin-6, and risk of mortality in older women the women's health and aging study. Circulation 103, 947-953. doi: 10.1161/01.CIR.103.7.947

von Büdingen, H.-C., Kuo, T. C., Sirota, M., van Belle, C. J., Apeltsin, L., Glanville, J., et al. (2012). B cell exchange across the blood-brain barrier in multiple sclerosis. J. Clin. Invest. 122:4533. doi: 10.1172/JCI63842

Wager-Smith, K., and Markou, A. (2011). Depression: a repair response to stress-induced neuronal microdamage that can grade into a chronic neuroinflammatory condition? Neurosci. Biobehav. Rev. 35, 742-764. doi: 10.1016/j.neubiorev.2010.09.010

Walker, A., Kavelaars, A., Heijnen, C., and Dantzer, R. (2014). Neuroinflammation and comorbidity of pain and depression. Pharmacol. Rev. 66, 80-101. doi: $10.1124 /$ pr.113.008144

Wenk, G. L. (2003). Neuropathologic changes in Alzheimer's disease. J. Clin. Psychiatry 64, 7-10.

Wilson, S. P., and Cassel, S. L. (2010). Inflammasome-mediated autoinflammatory disorders. Postgrad. Med. 122, 125-133. doi: 10.3810/pgm.2010.09.2209

World Health Organization. (2014). The Top 10 Causes of Death. Available online at: http://www.who.int/mediacentre/factsheets/fs310/en/ [Updated: May 2014; Cited: 20145 June].

Yasojima, K., Schwab, C., McGeer, E. G., and McGeer, P. L. (1999). Upregulated production and activation of the complement system in Alzheimer's disease brain. Am. J. Pathol. 154, 927-936. doi: 10.1016/S0002-9440(10) 65340-0

Younger/Early Onset Alzheimer's and Dementia: Alzheimer's Association. (2014). Available online at: http://www.alz.org/alzheimers_disease_early_onset.asps [Cited: 201413 May].

Zhang, Y., Liu, L., Peng, Y. L., Liu, Y. Z., Wu, T. Y., Shen, X. L., et al. (2014). Involvement of inflammasome activation in lipopolysaccharideinduced mice depressive-like behaviors. CNS Neurosci. Ther. 20, 119-124. doi: $10.1111 / \mathrm{cns} .12170$

Zitvogel, L., Kepp, O., Galluzzi, L., and Kroemer, G. (2012). Inflammasomes in carcinogenesis and anticancer immune responses. Nat. Immunol. 13, 343-351. doi: $10.1038 /$ ni.2224

Conflict of Interest Statement: The presented work is supported by the National Health and Medical Research Council Australia (APP 1043771 to Bernhard T. Baune). The funders had no role in study design, data collection and analysis, decision to publish, or preparation of the manuscript. The authors declare that the research was conducted in the absence of any commercial or financial relationships that could be construed as a potential conflict of interest.

Received: 01 August 2014; accepted: 18 September 2014; published online: 07 October 2014.

Citation: Singhal G, Jaehne EJ, Corrigan F, Toben C and Baune BT (2014) Inflammasomes in neuroinflammation and changes in brain function: a focused review. Front. Neurosci. 8:315. doi: 10.3389/fnins.2014.00315

This article was submitted to Neuroendocrine Science, a section of the journal Frontiers in Neuroscience.

Copyright (c) 2014 Singhal, Jaehne, Corrigan, Toben and Baune. This is an openaccess article distributed under the terms of the Creative Commons Attribution License (CC BY). The use, distribution or reproduction in other forums is permitted, provided the original author(s) or licensor are credited and that the original publication in this journal is cited, in accordance with accepted academic practice. No use, distribution or reproduction is permitted which does not comply with these terms. 